\title{
Correction to: Effects of enriched-potassium diet on cardiorespiratory outcomes in experimental non-ischemic chronic heart failure
}

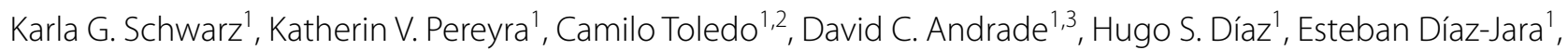
Domiziana Ortolani ${ }^{1}$, Angélica Rios-Gallardo ${ }^{1,2}$, Paulina Arias ${ }^{1}$, Alexandra Las Heras ${ }^{1}$, Ignacio Vera ${ }^{1}$, Fernando C. Ortiz ${ }^{4}$, Nibaldo C. Inestrosa ${ }^{2,6}$, Carlos P. Vio ${ }^{5,6}$ and Rodrigo Del Rio ${ }^{1,2,6^{*}}$ (1)

\section{Correction to: Biological Research (2021) 54:43}

https://doi.org/10.1186/s40659-021-00365-z

Following publication of the original article [1], the Figs. 2, 3 and 4 are misplaced. The correct order of figures is given in this erratum (Figs. 1, 2, 3, 4, 5, 6).

The original article has been corrected. original author(s) and the source, provide a link to the Creative Commons licence, and indicate if changes were made. The images or other third party material in this article are included in the article's Creative Commons licence, unless indicated otherwise in a credit line to the material. If material is not included in the article's Creative Commons licence and your intended use is not permitted by statutory regulation or exceeds the permitted use, you will need to obtain permission directly from the copyright holder. To view a copy of this licence, visit http://creativecommons.org/licenses/by/4.0/. The Creative Commons Public Domain Dedication waiver (http://creativeco mmons.org/publicdomain/zero/1.0/) applies to the data made available in this article, unless otherwise stated in a credit line to the data. 


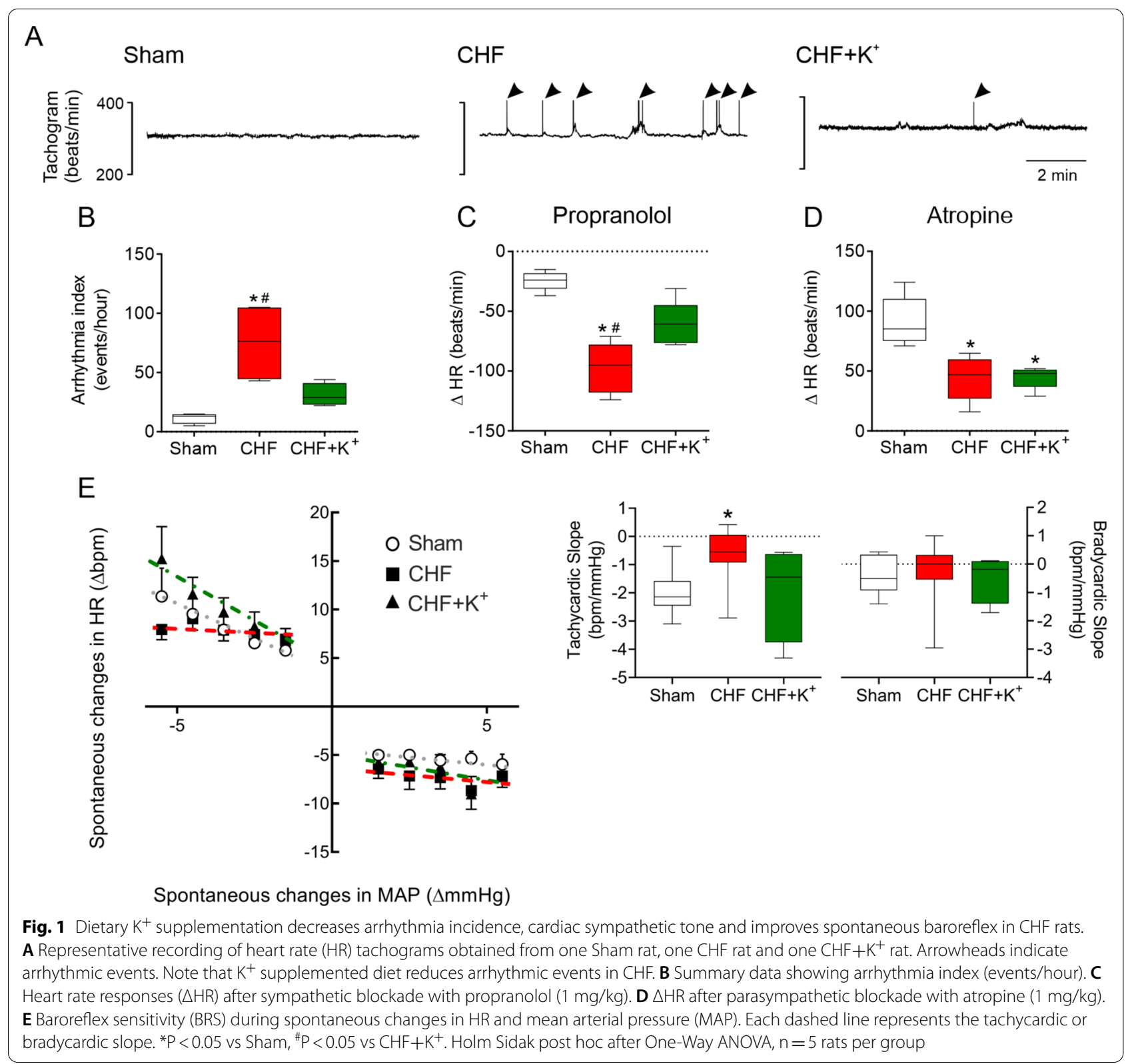




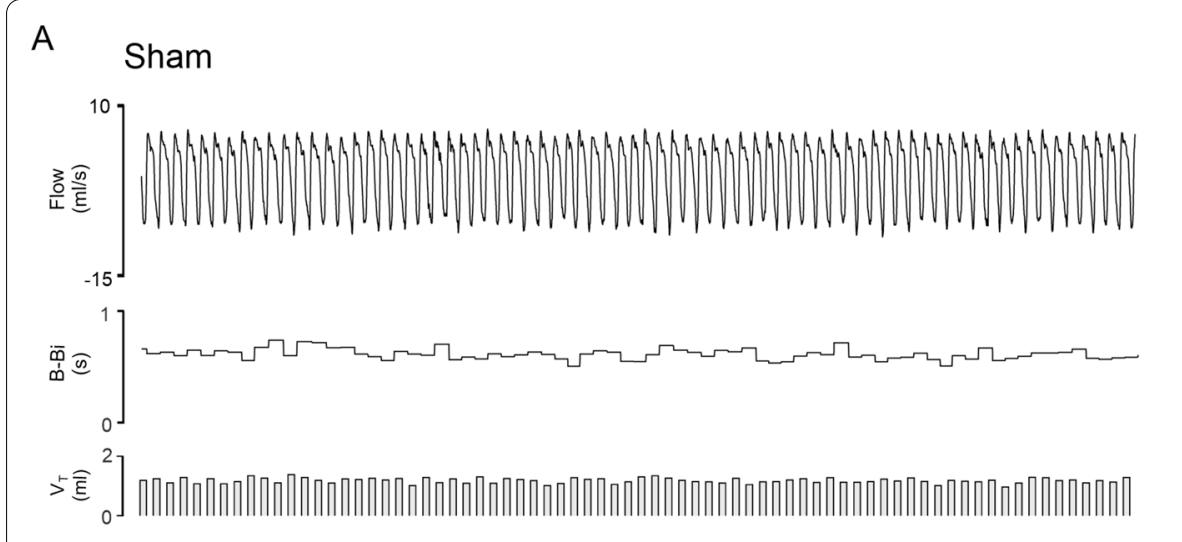

B
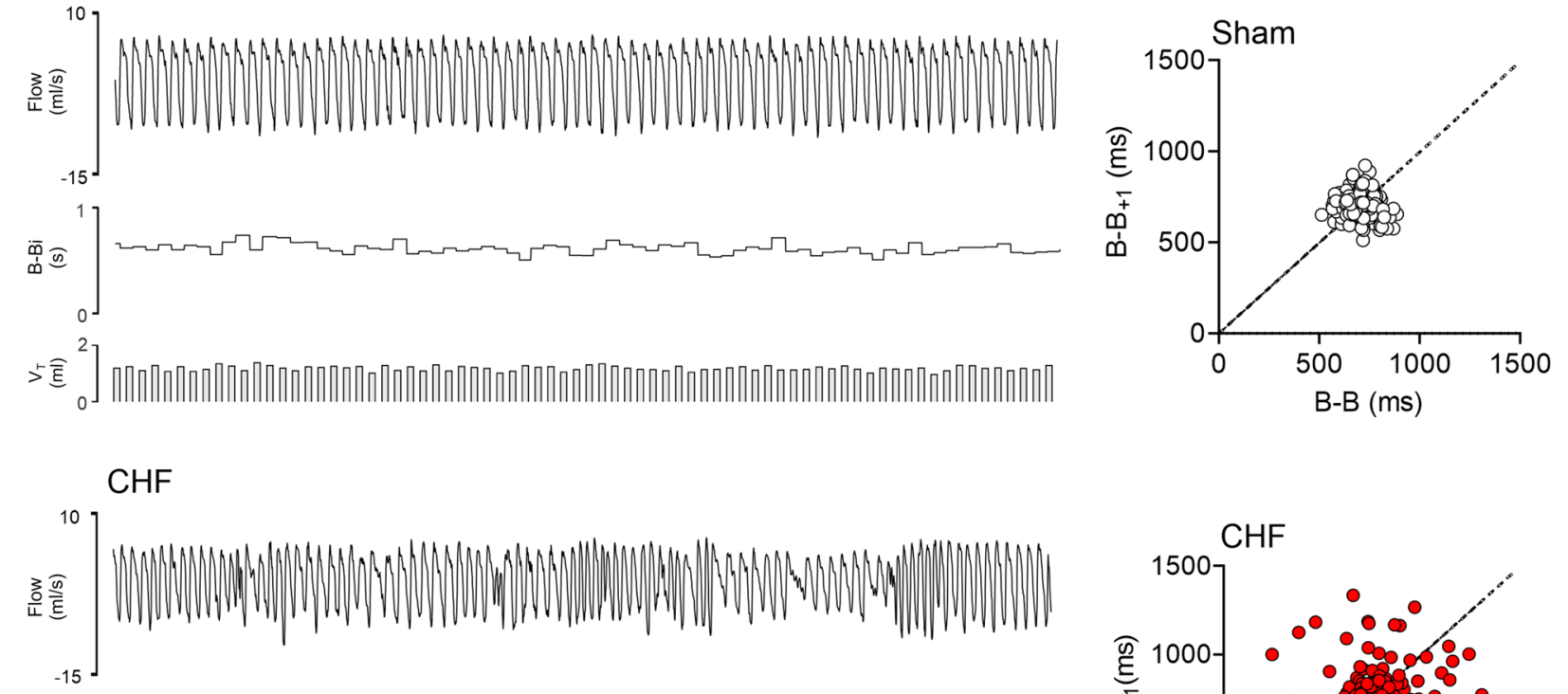

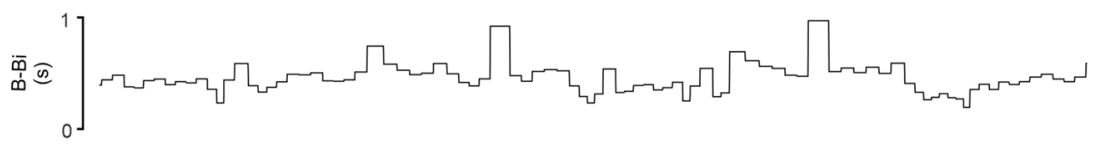

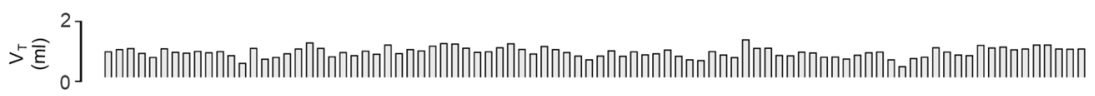
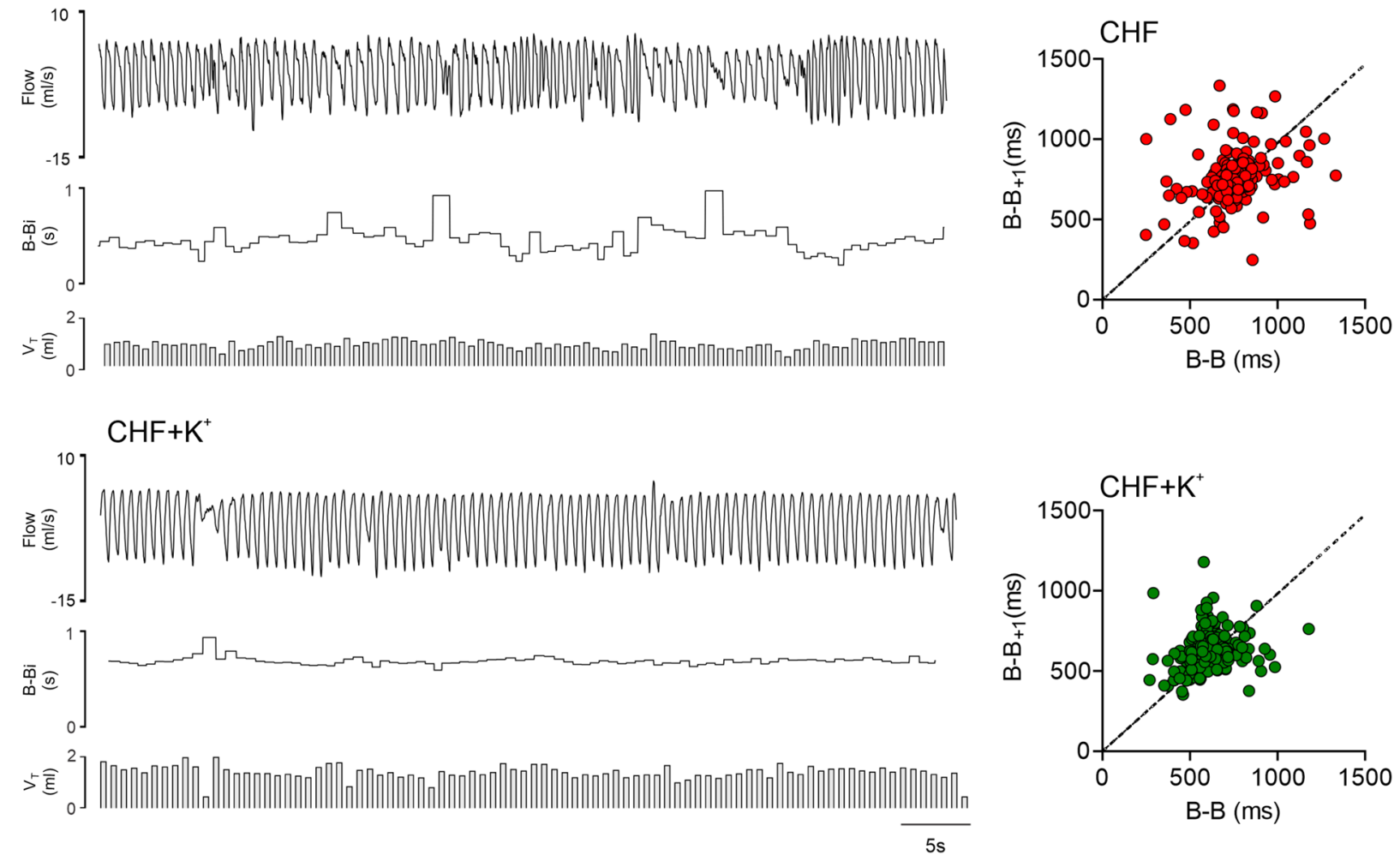

C

D

E

$\mathrm{F}$
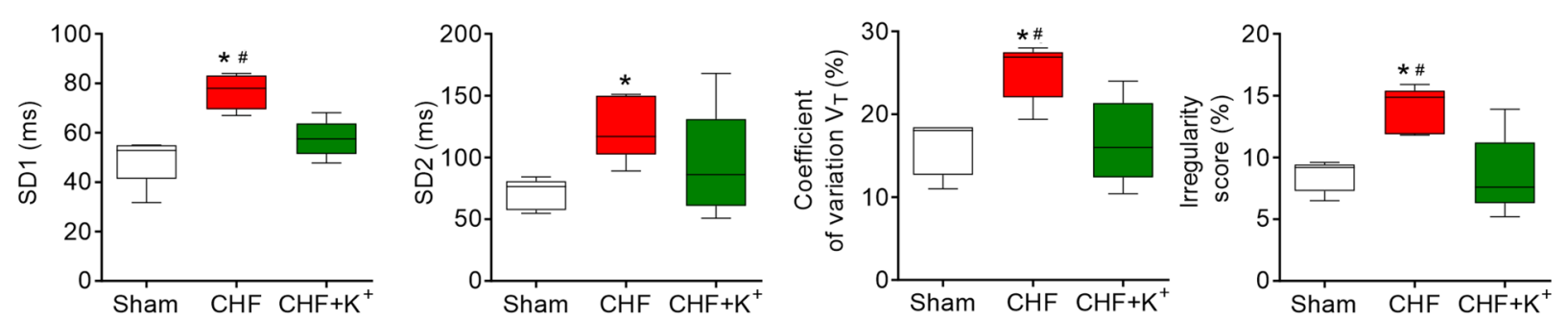

Fig. 2 Daily dietary $\mathrm{K}^{+}$supplementation improves breathing in $\mathrm{CHF}$ rats. A Representative ventilation recordings of ventilatory flow $(\mathrm{ml} / \mathrm{s})$, breath-to-breath interval $\left(B-B_{i}, s\right)$ and tidal volume $\left(V_{T}, m l\right)$ obtained from one Sham rat, one $C H F$ rat and one $C H F+K^{+}$rat. B Representative Poincare plots showing $B-B_{i}$ variability. C-D Summary data displaying SD1 and SD2 in all groups. Note that irregularity of B- $B_{i}$ in $C H F$ is markedly improve by dietary $\mathrm{K}^{+}$supplementation. $\mathbf{E}$ Summary data showing changes in breathing irregularity score (\%). $\mathbf{F}$ Coefficient of variation of $\mathrm{V}_{\mathrm{T}}$ amplitudes (\%). $\mathrm{K}^{+}$supplemented diet significantly reduces $\mathrm{V}_{T}$ oscillations in $\mathrm{CHF} .{ }^{*} \mathrm{P}<0.05$ vs Sham, ${ }^{\#} \mathrm{P}<0.05$ vs $\mathrm{CHF}+\mathrm{K}^{+}$. Holm Sidak post hoc after One-Way ANOVA, $n=5$ rats per group 


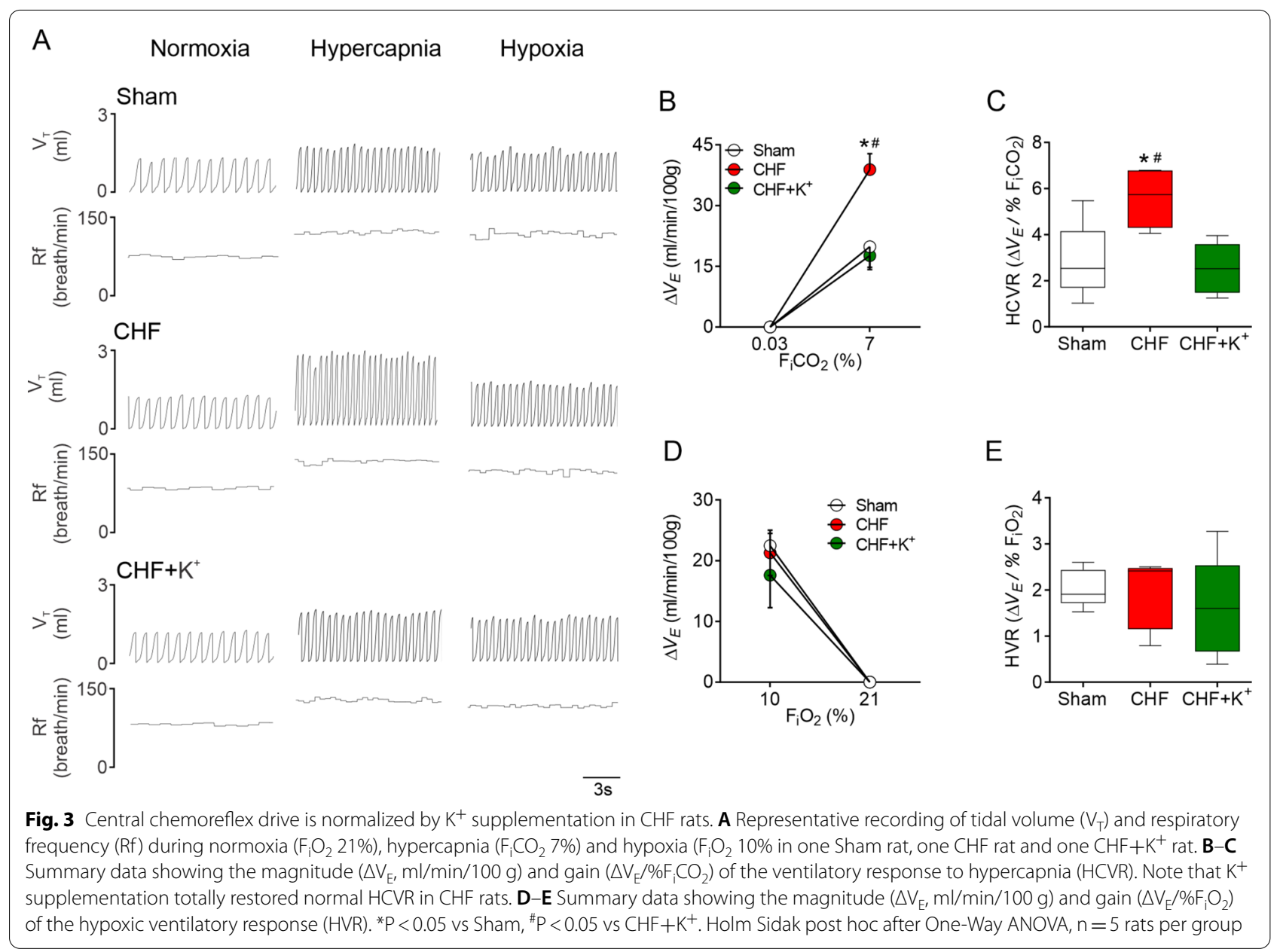




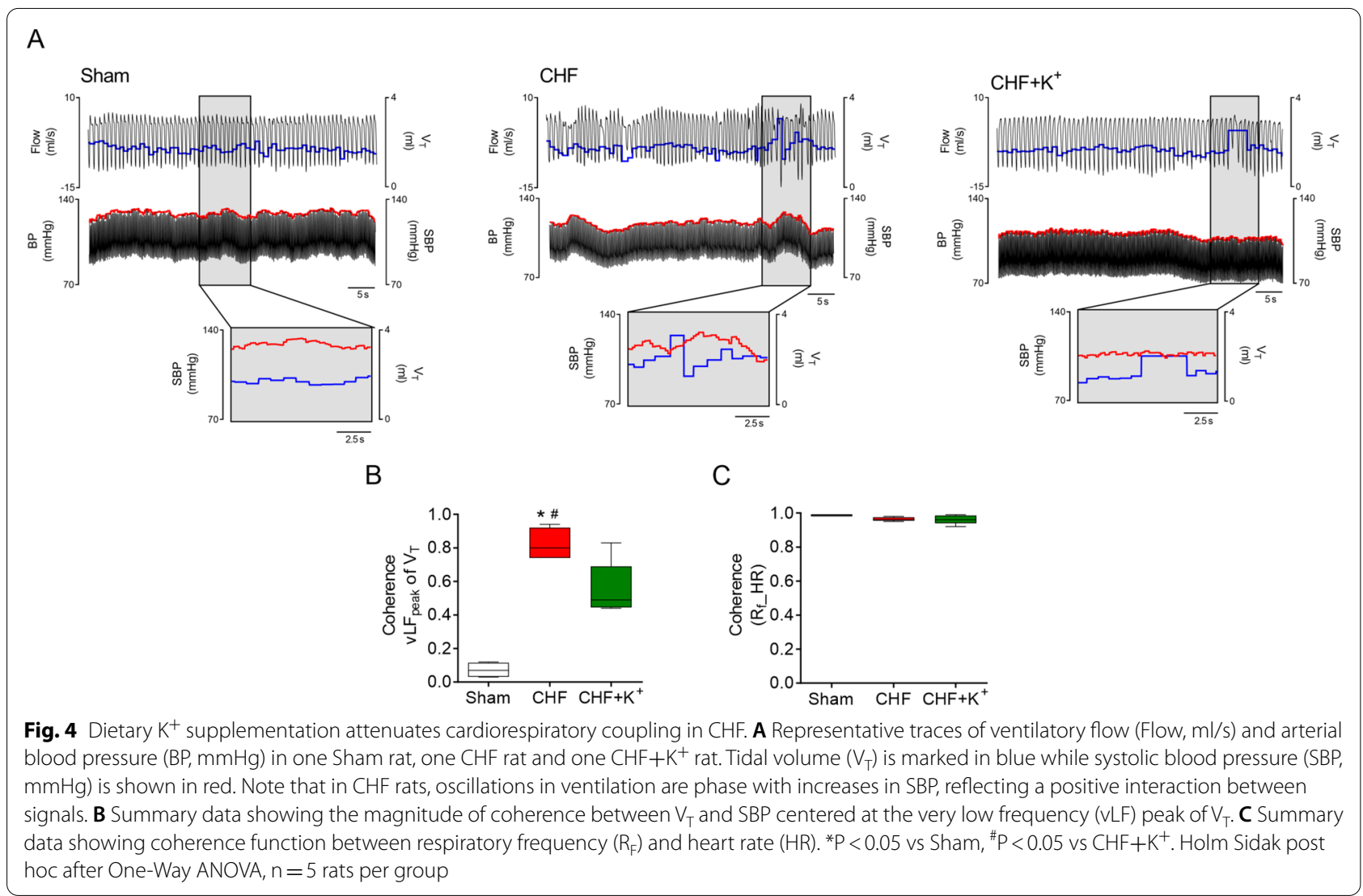




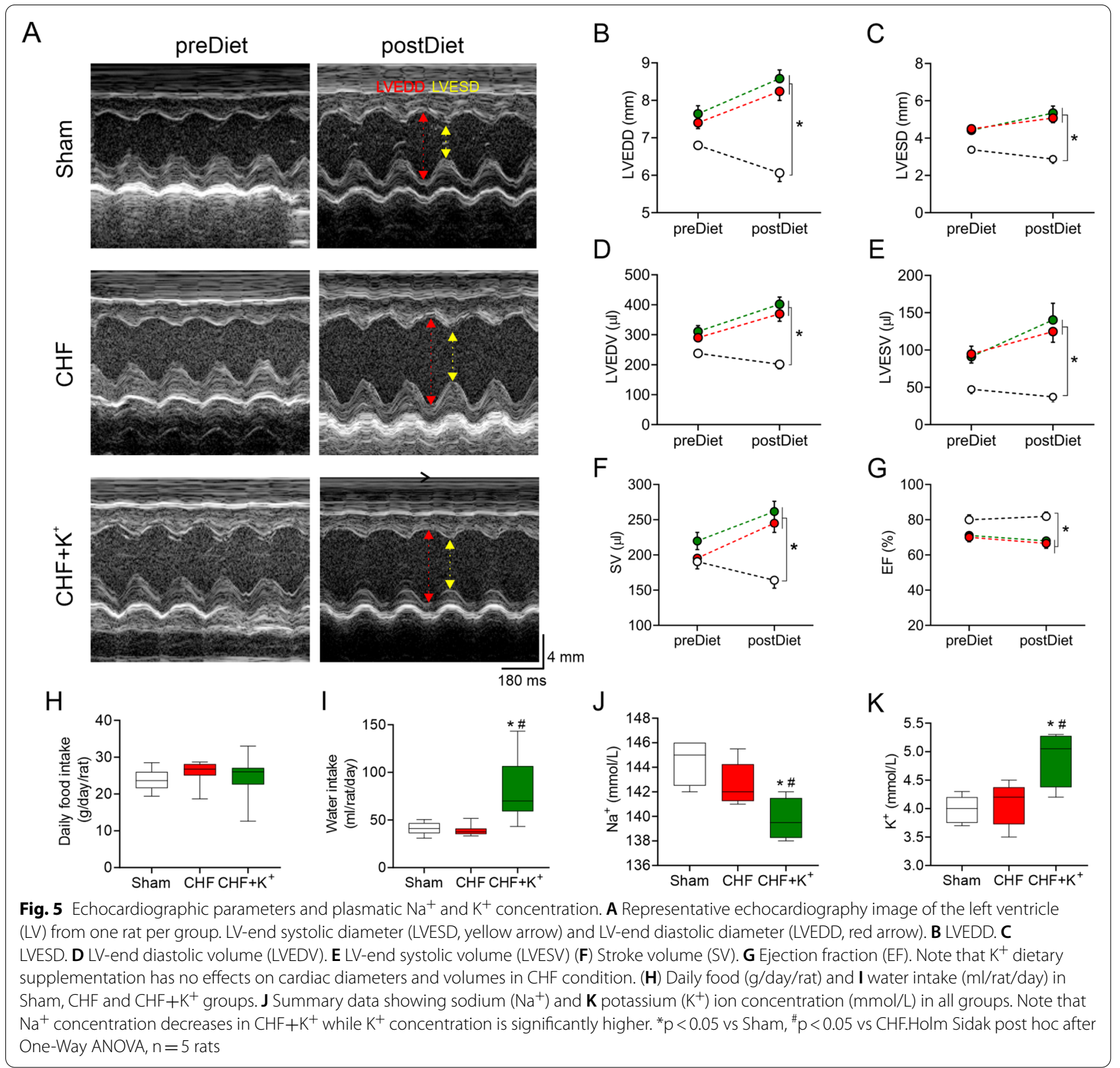




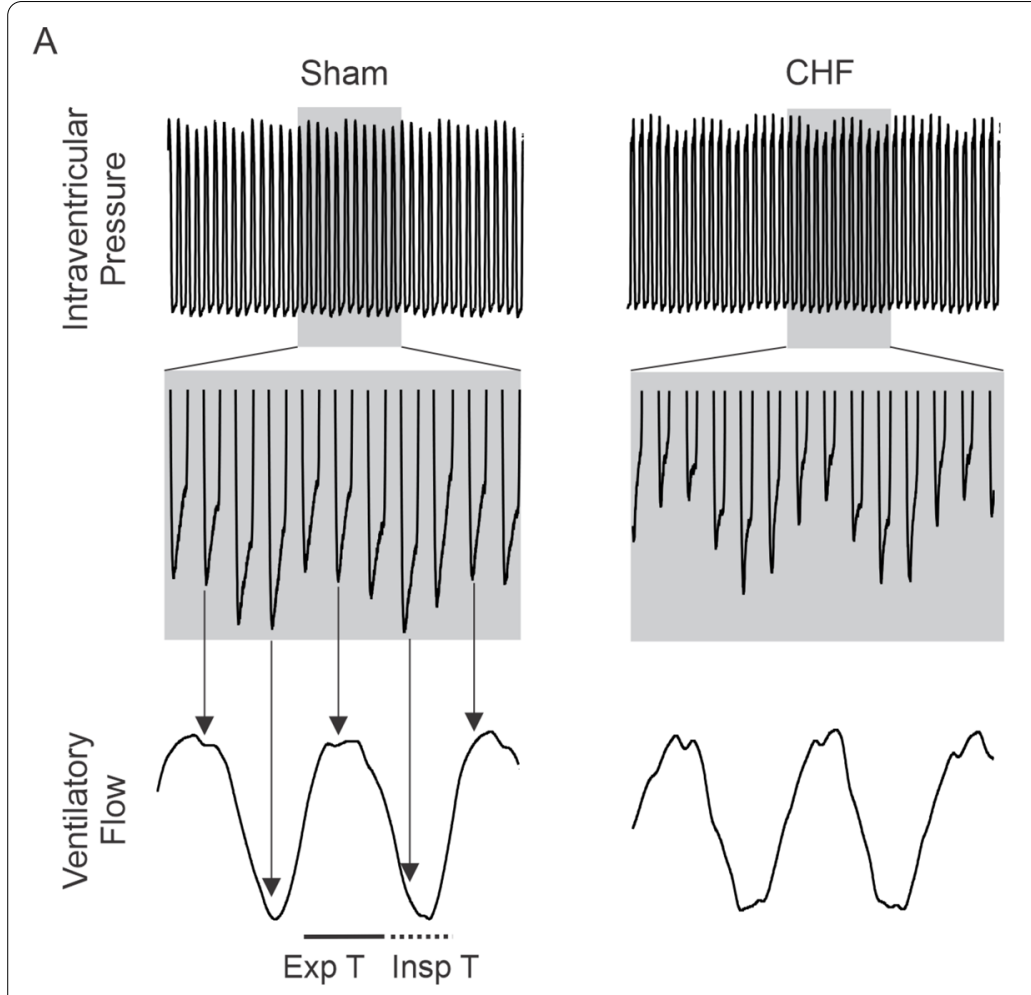

B
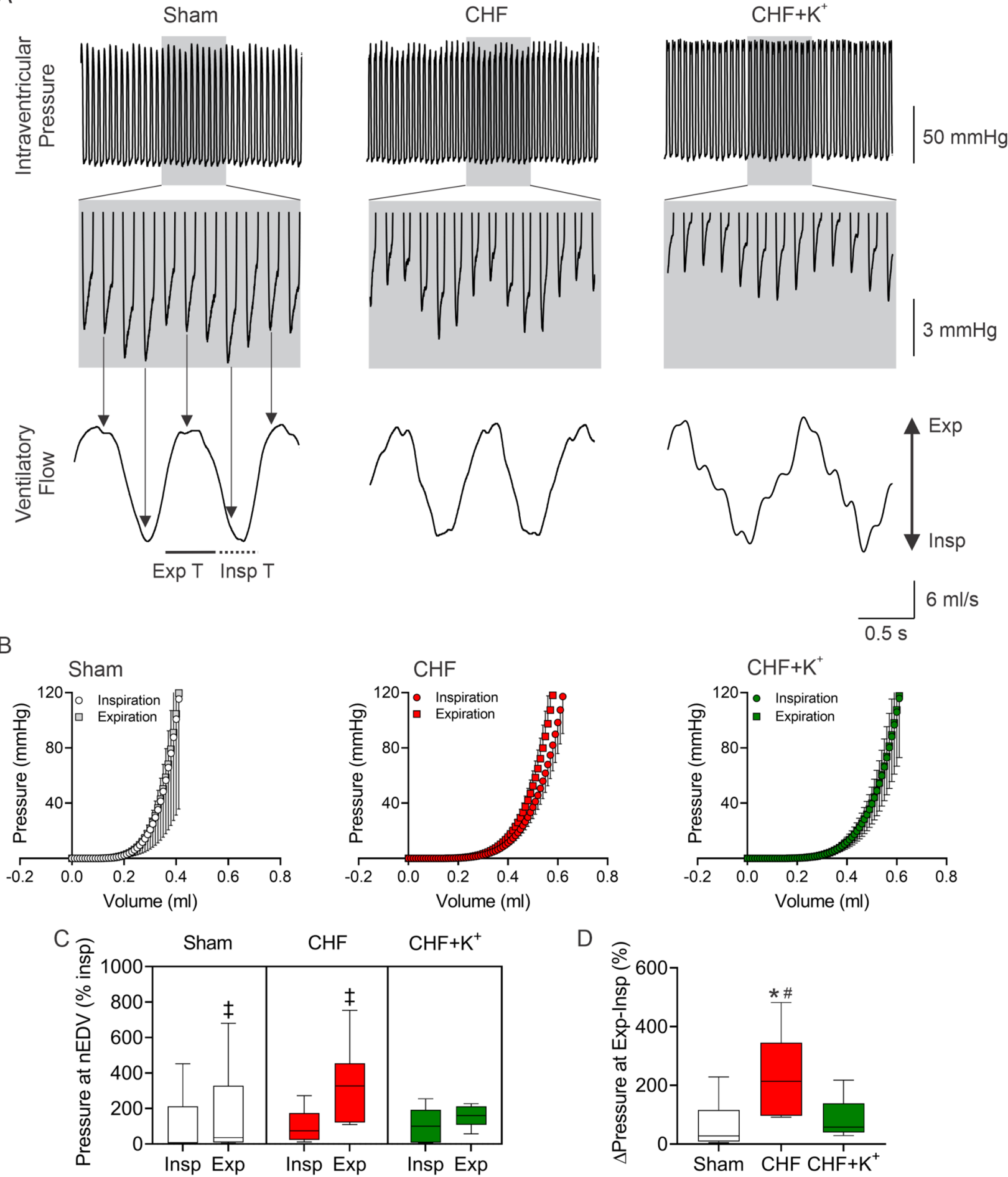

Fig. 6 Dietary $\mathrm{K}^{+}$supplementation improves cardiac diastolic function in CHF rats. A Representative recording of left ventricle (LV) intraventricular pressure from one Sham rat, one $\mathrm{CHF}$ rat and one $\mathrm{CHF}+\mathrm{K}^{+}$rat (Upper panel). Lower panel shows ventilatory flows in each section. Note that end diastolic pressure (EDP) is modulated by the ventilatory cycle. B End diastolic pressure volume relationship assessed by single-beat PV-loop analysis during the expiratory and inspiratory phases of the breathing cycle. C Summary data of normalized EDP (nEDP) during inspiration and expiration. Note that the EDP was severely modulated by the ventilatory cycle in CHF rats and this was abolished by $\mathrm{K}^{+}$diet supplementation. D Summary data showing percent changes in $\triangle$ intraventricular pressures at Exp-Insp. Two-way ANOVA (C) and One-way ANOVA (D), followed by Holm Sidak posthoc. ${ }^{\ddagger} \mathrm{P}<0.05$ vs. Insp; ${ }^{*} \mathrm{P}<0.05$ vs. Sham, $\# \mathrm{P}<0.05$ vs $\mathrm{CHF}+\mathrm{K}^{+} \mathrm{n}=5$ rats per group 


\section{Author details}

${ }^{1}$ Laboratory of Cardiorespiratory Control, Department of Physiology, Pontificia Universidad Católica de Chile, Santiago, Chile. ${ }^{2}$ Centro de Excelencia en Biomedicina de Magallanes (CEBIMA), Universidad de Magallanes, Punta Arenas, Chile. ${ }^{3}$ Centro de Fisiología y Medicina de Altura, Departamento Biomedico, Facultad de Ciencias de la Salud, Universidad de Antofagasta, Antofagasta, Chile. ${ }^{4}$ Mechanisms of Myelin Formation and Repair Laboratory, Instituto de Ciencias Biomédicas, Facultad de Ciencias de Salud, Universidad Autónoma de Chile, Santiago, Chile. ${ }^{5}$ Facultad de Medicina y Ciencia, Universidad San Sebastián, Santiago, Chile. ${ }^{6}$ Centro de Envejecimiento y Regeneración (CARE), Pontificia Universidad Católica de Chile, Santiago, Chile.

Published online: 21 January 2022

\section{Reference}

1. Schwarz KG, Pereyra KV, Toledo C, Andrade DC, Díaz HS, Díaz-Jara E, Ortolani D, Rios-Gallardo A, Arias P, Las Heras A, Vera I. Effects of enrichedpotassium diet on cardiorespiratory outcomes in experimental nonischemic chronic heart failure. Biol Res. 2021;54(1):43.

\section{Publisher's Note}

Springer Nature remains neutral with regard to jurisdictional claims in published maps and institutional affiliations. 